\title{
ÇOK KATLI YAPILARDA ROBOTIK LAZER TARAYICI SİSTEMLERLE YAPISAL SAĞLIK TAKİBİ
}

\author{
Muammer ÖZBEK \\ Yiğit Dağhan GÖKDEL**
}

\begin{abstract}
Alınma:27.07.2018; kabul:03.12.2018
Öz: Bu çalışmada çok katlı bina, köprü vb. yapıların anlık sağlık durumlarının takibinde kullanılmak amacıyla uzaktan algılama ve temassız ölçüm tekniklerine dayalı, programlanabilir robotik bir tarayıcı sistem geliştirilmesi amaçlanmaktadır. Önerilen sistem, ölçüm tekniği olarak lazer Doppler interferometri kullanılacağı için test edilen yapılar üzerine herhangi bir sensör yerleştirilmesine ihtiyaç duyulmadan her türlü yapıya kolaylıkla uygulanabilir. Yüksek hassasiyet ve çözünürlükte ölçüm alınabilmesi amacıyla, yüksek örnekleme frekansına sahip bir lazer Doppler titreşimölçer, yatay ve düşey eksenlerde bağımsız hareket edebilen motorize bir platform üzerine yerleştirilmiştir. Platforma eklenen kameralı görüntüleme sistemleri, geliştirilen kontrol algoritmaları ve arayüz yardımıyla, kullanıcının test ve ölçümler ile ilgili çeşitli parametreleri kişisel bilgisayarı üzerinden kontrol edebileceği bütünleşik bir yapı oluşturulmuştur. Geliştirilen tarayıcı sistem laboratuvarda kurulan küçük ölçekli çok katlı bina modelleri üzerinde test edilerek yapıların dinamik özelliklerinin yüksek doğruluk ve çözünürlükte çıkarılabildiği gösterilmiştir. Önerilen sistem birden fazla yapının düzenli bir şekilde taranmasına imkan sağlayacak şekilde programlanabilmektedir. Elde edilen titreşim verisinin analizi sonucunda yapının doğal frekanslarının, sönümleme oranlarının ve mod şekillerinin hızlı ve etkin bir şekilde hesaplanabildiği görülmüştür.
\end{abstract}

Anahtar Kelimeler: Yapısal sağlık takibi, Robotik sistemler, Titreşim ölçümü, Modal analiz, Lazer interferometri, Rüzgar ve deprem salınımı

\section{Structural Health Monitoring of Multi-story Buidings via Robotic Laser Scanning Systems}

\begin{abstract}
This study aims to develop a programmable robotic scanning system, which is based on remote sensing and non-contact measurement techniques, for structural health monitoring of multi-story buildings, bridges and similar structures. The proposed system is based on laser Doppler interferometry and can easily be applied to almost all kinds of structures without needing to install any sensors on the structure. In order to take measurements with high accuracy and spatial resolution, the utilized laser Doppler vibrometer is mounted on a motorized platform which can independently rotate about the horizontal and vertical axes. A unified monitoring system, which enables user to control several test parameters through a personal computer, was formed by means of the integrated camera imaging system, control algorithms and user interface. The developed scanning system was tested in the lab on small scale multi-story building models and it was demonstrated that the dynamic properties of the structure can be extracted with high accuracy and resolution. The proposed system can be programmed to scan several structures successively by using the same device. The analysis results show that natural frequencies, damping ratios and mode shapes of the test structures can be extracted in a fast and efficient way.
\end{abstract}

Keywords: Structural health monitoring, Robotic systems, Vibration measurement, Modal Analysis, Laser interferometry, Wind and earthquake response.

\footnotetext{
* Muammer ÖZBEK, İstanbul Bilgi Üniversitesi, İnşaat Mühendisliği Bölümü, 34060, Eyüp, İstanbul

** Yiğit Dağhan GÖKDEL, İstanbul Bilgi Üniversitesi, Elektrik- Elektronik Müh. Bölümü, 34060, Eyüp, İstanbul

İletişim Yazarı: Muammer ÖZBEK (muammer.ozbek@bilgi.edu.tr)
} 


\section{GİRIŞ}

Yapıların dinamik özelliklerinin ve sağlık durumlarının hızlı ve etkin bir şekilde ölçülmesi ve belirlenebilmesi son yıllarda üzerinde en çok yoğunlaşılan araştırma konuları arasında yer almaktadır. Sensör teknolojileri ve analiz metotlarındaki gelişmelere paralel olarak bu konuda önemli ilerlemeler sağlanmış olsa da boyut ve kullanım olarak aynı hızla gelişen ve karmaşıklaşan yapı sistemleri üzerinde istenilen amaçlara ulaşılabilmesi için ölçüm ve veri analizi gibi konularda hala çözümlenmesi gereken önemli problemler mevcuttur.

Yapılar üzerinde gerçekleştirilen test ve ölçümlerde yap1 üzerine ivme ölçerler ve gerinim ölçerler yerleştirilmesi en sık başvurulan yöntemdir Magalhães ve Cunha (2016). Ancak bu sensör türlerinin uygulanabilmesi için güç ve/veya veri aktarımı amacıyla kablo vb. altyapı çalışmalarının yapılması ve yüksek maliyetli veri toplama sistemlerinin kurulumu gerekmektedir (Oliveira ve diğ., 2017). Özellikle büyük boyuttaki yapılar üzerinde yüksek çözünürlükte ölçüm alınabilmesi için çok sayıda sensörün birarada kullanılacağı karmaşık test düzeneklerine ihtiyaç duyulmaktadır. Talep edilen çözünürlüğe bağlı olarak sensör sayısı arttıkça, elde edilen verinin toplanması, depolanması ve işlenmesi, yüksek kapasiteli ve maliyetli sistemler kullanılmasını zorunlu hale getirmektedir.

Veri aktarımı için alternatif bir çözüm olarak kablosuz ağ sistemleri kullanılabilir ancak güç aktarımı için kablolama vb. hazırlıkların yapılması zorunludur. Öte yanda kablosuz ağa bağlı sistemler tercih edildiğinde kablolu sistemler için çok da risk oluşturmayan senkronizasyon problemi daha kritik hale gelebilmektedir. Çok sayıda sensörün eşzamanlı çalıştığı bu tür sistemlerde veri akışında istenilen sürekliliğin ve senkronizasyonun sağlanamaması gibi problemler sıklıkla yaşanmaktadır (Bocca ve diğ., 2011). Numerik modeller ve saha testleri üzerinde yapılan çalışmalar çok küçük zaman kaymalarının bile mod şekillerini önemli ölçüde etkileyebildiğini ortaya koymuştur. Özellikle yapısal sağlık kontrolü gibi mod şekillerindeki hassasiyetin önemli olduğu uygulamalarda senkronizasyon problemi elde edilen sonuçlarda tutarsızlıklara ve yanlış tahminlere yol açabilmektedir (Krishnamurthy ve di ̌̆g., 2008).

Ölçülmesi planlanan deformasyonun türü de kullanılacak olan sensör seçiminde belirleyici rol oynamaktadır. Mesela rüzgar yükleri altında salınım yapan bina veya köprü türü yapıların deformasyonları sadece ivme ölçer kullanılarak hassas bir şekilde tespit edilememektedir. Rüzgar yükleri tarafından oluşturulan deformasyonlar, ortalama rüzgar hızından kaynaklanan statik deformasyon ve türbülanstan kaynaklanan dinamik deformasyon olmak üzere iki bileşenden oluşur (Tamura ve diğ., 2002). İvme ölçerler statik deformasyon kısmının ölçülmesinde yetersiz kaldığı için pek çok bilim insanı yapıların rüzgar davranışının ölçülmesinde ivme ölçerlerin mutlaka GPS (Global Positioning System; Küresel Konumlama Sistemi) tabanlı sensörlerle beraber kullanılması gerektiğini belirtmiştir (Nickitopoulou ve di 2006). Bu iki sensörün beraber kullanımı ölçüm maliyetlerinde ek artışlara sebep olmaktadır.

$\mathrm{Bu}$ çalışmada, dinamik test ve ölçümlerin, mevcut sensör teknolojilerine kıyasla çok daha kısa sürelerde tamamlanmasını sağlayacak, benzer şekilde çok daha fazla sayıda noktadan ölçüm alınmasını mümkün kılarak ölçüm çözünürlüğünü artıracak yeni bir lazer ölçüm ve tarama sistemi geliştirilmesi amaçlanmaktadır.

\section{SİSTEM ve SENSÖR ÖZELLIKLERI}

\subsection{Lazer Titreşim Ölçüm Sistemleri}

Lazer Doppler titreşimölçerler, sahip oldukları yüksek örnekleme frekansı ve ölçüm hassasiyeti gibi önemli avantajlar sebebiyle yapılar üzerinde gerçekleştirilen test ve ölçümlerde artan bir yoğunlukta kullanılmaktadır. Bu sistemde lazer kaynağı (laser head) hem verici hem de alıcı olarak çalışmaktadır. Kaynaktan çıkan ve ölçülecek olan hedef cisme yönlendirilen lazer ışıları yüzeyden yansıdıktan sonra yine aynı sensör tarafından algılanmakta ve Doppler 
prensibine göre işlenmektedir. Hedefe gönderilen ve geri yansıyan 1şın demetleri arasında oluşan dalga boyu ve faz farklarının analiz edilmesi sayesinde hedef cismin hızı ve ötelenmesi hesaplanabilmektedir (Yang ve Allen, 2012).

Çok farklı çeşit ve özellikte lazer türleri olmakla beraber inşaat mühendisliği uygulamaları için tercih edilen mevcut titreşimölçerlerde sıklıkla $500 \mathrm{~nm}$ ve $680 \mathrm{~nm}$ arasında değişen dalga boylarına sahip kırmızı/yeşil görünür lazer ışınları kullanılmaktadır. Kaynağın gücüne de bağlı olarak 400 metreye kadar mesafelerden ölçüm alınmasını mümkün kılan bu görünür lazer ışınlarının maalesef çoğu yüzeyden yansıma yoğunlukları yüksek değildir. Bu sebeple hedef cisim üzerinde, özel boyalar veya yansıtıcı etiketler yardımıyla yüzey iyileştirilmesi yapılması gerekmektedir. Bu sistemlerde lazer kaynağı sabit konumdadır. Lazer 1şınları kaynaktan çıkar çıkmaz yine cihaz içinde bulunan ayna ve mercekler yardımıyla hedefe yönlendirilip otomatik tarama modunda kullanılabilirler. Tarama fonksiyonu ayna ve merceklerin bir bilgisayar yardımıyla kontrollü bir şekilde hareket ettirilmesi sayesinde mümkün olabilmektedir.

Görünür lazerlerden farklı olarak kızıl ötesi, IR (infra-red) lazer 1şınları hedef yüzey üzerinde özel bir işlem veya hazırlık gerektirmeden pekçok madde tarafindan yüksek yoğunlukla yansıtılmaktadır. Işın kaynağının gücüne bağlı olarak IR lazer sistemleriyle 400 metre ve üstü mesafelerden ölçümler alınabilmektedir. Ancak görünür dalga boyundaki yeşi1/kırmızı lazerlerden farklı olarak IR 1şınlar ayna ve mercek gibi sistemlerle yönlendirilemediği için kullanımları sınırlıdır ve otomatik tarama modunda kullanılamazlar. Mevcut IR lazer titreşimölçerlerde, IR ve görünür dalga boyunda olmak üzere 2 farklı lazer eşzamanlı olarak kullanılmaktadır. Yüksek yansıma yoğunluğuna sahip IR lazer 1şınları, titreşim ölçümleri için kullanılmaktadır. Ancak kızıl ötesi dalga boyunda olan bu lazer normal gözle görülemediği için lazer kaynağının ölçüm anında hangi noktayı hedeflediğinin anlaşılabilmesi amacıyla ölçüm lazerine ek olarak, görünür dalga boyunda yeşil/kırmızı bir hedefleme lazerine de ihtiyaç duyulmaktadır. Kullanıcı hedefleme lazeri yardımıyla yapı üzerinde istediği ölçüm noktasını manuel olarak seçer. İki farklı lazer kaynağı aynı noktayı gösterecek şekilde ayarlandığı için IR lazer de aynı noktaya dolaylı olarak yönlendirilmiş olur.

$\mathrm{Bu}$ çalışmada, yukarıda bahsedilen ayna, mercek vb. optik sistemlere ihtiyaç duyulmadan doğrudan lazer kaynağının kendisinin motorize bir platform yardımıyla hedefe yönlendirilmesi ve bu sayede yapı üzerinde çok sayıda noktanın lazer ışınlarıyla taranması amaçlanmıştır. IR lazer gözle görülemediği için, laboratuvar ortamında gerçekleştirilen ilk yapılabilirlik testlerinde, kırmızı ölçüm lazerine sahip bir sistem, Polytec CLV-2534, (https://www.polytec.com/int/) kullanılmıştır. Bu sayede 1şınların istenilen hedefe ne doğrulukta yönlendirilebildiği ve platformun hareketini sağlayan kontrol mekanizmalarının etkinliği kolaylıkla test edilebilmiştir.

Lazer ölçümlerine ek olarak yapı üzerine yerleştirilen 15 adet ivme ölçer yardımıyla eşzamanlı titreşim ölçümleri de alınmış ve hesaplanan dinamik özelliklerin doğruluğu kontrol edilebilmiştir. Bu ivme ölçerler her iki yatay yönde eğilme ve burulma modlarını gözlemleyecek şekilde yerleştirilmiştir.

\subsection{Motorize Platform ve Kontrol Sistemi}

Lazer ışınlarının otomatik tarama modunda hızlı bir şekilde hedefe yönlendirilebilmesi için geliştirilen sistem aşağıda Şekil 1'de görülmektedir. Bu amaçla lazer kaynağı yatay ve düşey olmak üzere 2 farklı eksende bağımsız hareket edebilen bir platform üzerine yerleştirilmiştir. Platformun hareketi 2 adet adım (step) motoru ile sağlanmaktadır. Kullanılan adım motorları $0,014^{\circ}$ açı hassasiyetine sahiptir. Platform üzerine yerleştirilen kamera sistemi ile test edilecek yapının anlık görüntüsü bilgisayara aktarılabilmekte ve ölçüm süresi, test noktaları gibi çeşitli deney parametreleri geliştirilen arayüz sayesinde bilgisayar üzerinden kontrol edilebilmektedir. Arayüz ve adım motorları arasındaki haberleşme bir mikro-kontrol devresi yardımıyla sağlanmaktadır. 


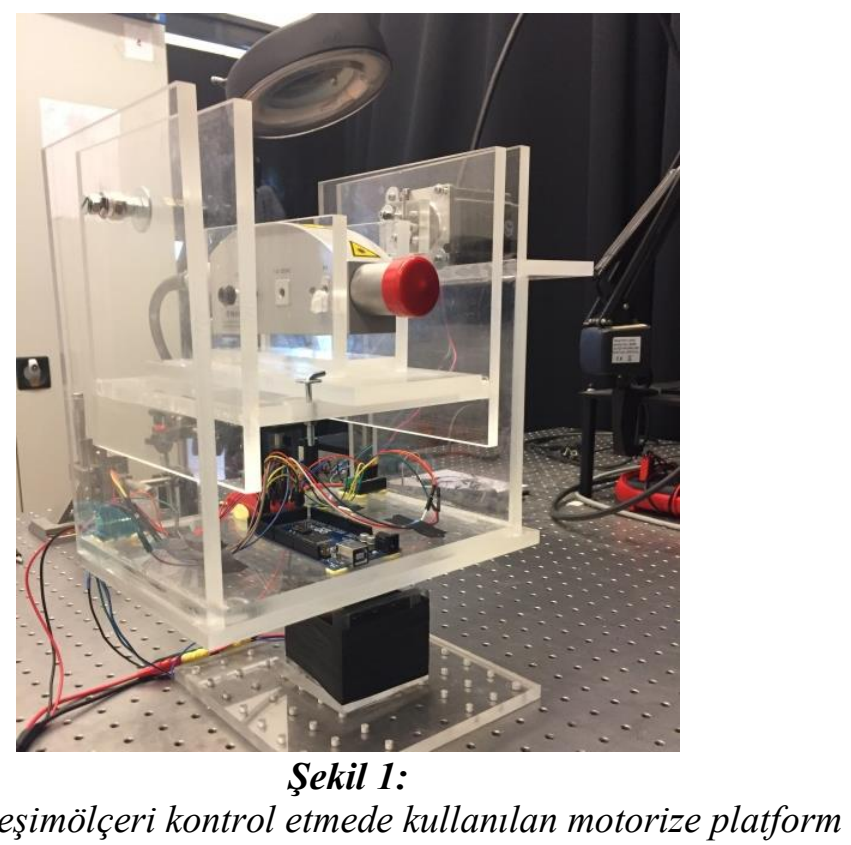

\section{TEST DÜZENEĞí}

Geliştirilen sistemin yapılar üzerinde seri ölçümler alınmasında kullanılabilirliğini sınamak adına yükseklikleri sırasıyla $1800 \mathrm{~mm}$ ve $2000 \mathrm{~mm}$ olan iki adet küçük ölçekli 6'şar katlı bina modeli kurulmuştur. Bu modeller üzerinde ölçüm alınacak noktalar, geliştirilen özel bir yazılım ve arayüz yardımıyla kullanıcı tarafından sisteme tanıtılarak cihaz otomatik tarama modu için programlanabilmektedir.

Ölçüm noktalarının sisteme tanıtılması iki farklı şekilde yapılabilir. Platforma bağlanan kamera yardımıyla alınan gerçekzamanlı ekran görüntüsü üzerinden, kullanıcı istediği noktaları fare yardımıyla tıklayarak seçebilir. Bilgisayar ekranından seçilen bu noktaların koordinatları sistem tarafından otomatik olarak hesaplanarak yatay ve düşey eksende gerekli dönüş açıları mikro-kontrol devresine aktarılır. Kontrol ünitesinden gelen komutlara göre hareket eden motorlar yardımıyla lazer kaynağı hedefe yönlendirilir.

Taranacak yapının, ekranda tamamı görülemeyecek kadar büyük olması durumunda kullanıcı, ölçüm noktalarını, lazeri platform yardımıyla yönlendirerek doğrudan yapı üzerinde seçebilir. Seçilen bu noktaların koordinatları hesaplanarak sistem hafızasında saklanır. Benzer şekilde iki nokta seçilip, seçilen noktalar arasında kalan doğru parçası eşit uzunlukta dilimlere parçalanabilir. Dilim ve ölçüm noktalarının sayısı için herhangi bir üst sınır bulunmamaktadır. Aşağıda Şekil 2'de test edilen model ve ek ölçümler için yerleştirilmiş ivme ölçerler görülmektedir.

Yapı üzerine, $\mathrm{X}$ ve $\mathrm{Y}$ yönlerinde titreşim ölçümü için toplam 15 adet tek eksenli ivmeölçer yerleştirilmiştir. Veri toplama sistemi olarak $200 \mathrm{~Hz}$ ölçüm frekansında 16 kanal okuma alabilen TestBox2010 model dinamik veri toplama sistemi kullanılmıştır. Katlara sabitlenen ağırlıklar yardımıyla farklı titreşim periyotlarına sahip modeller tasarlanabilmektedir. Şekil 2'de katlara sabitlenen metal blokların her biri $10 \mathrm{~kg}$, yapının ağırlıklarla beraber toplam kütlesi ise 75 kg'dır. Buna ek olarak modelin sabitlendiği plaka üzerine toplamda $200 \mathrm{~kg}$ kütleli metal bloklar yerleştirilerek yapının stabilitesi sağlanmıştır. Yapı üzerine yerleştirilen optik etiketler, ekran görüntüsü üzerinde seçilen noktalara lazerin ne doğrulukta hedeflenebildiğini kontrol etmek için kullanılmıştır.

Yapının yüksek frekanslı dinamik modlarının da uyarılabilmesi amacıyla yapıya, değişik noktalardan ani darbe şeklinde kuvvetler uygulanmış ve darbe sonrası serbest titreşim davranışı, mevcut ivme ölçerler ve lazer titreşimölçer ile eşzamanlı olarak ölçülmüştür. 


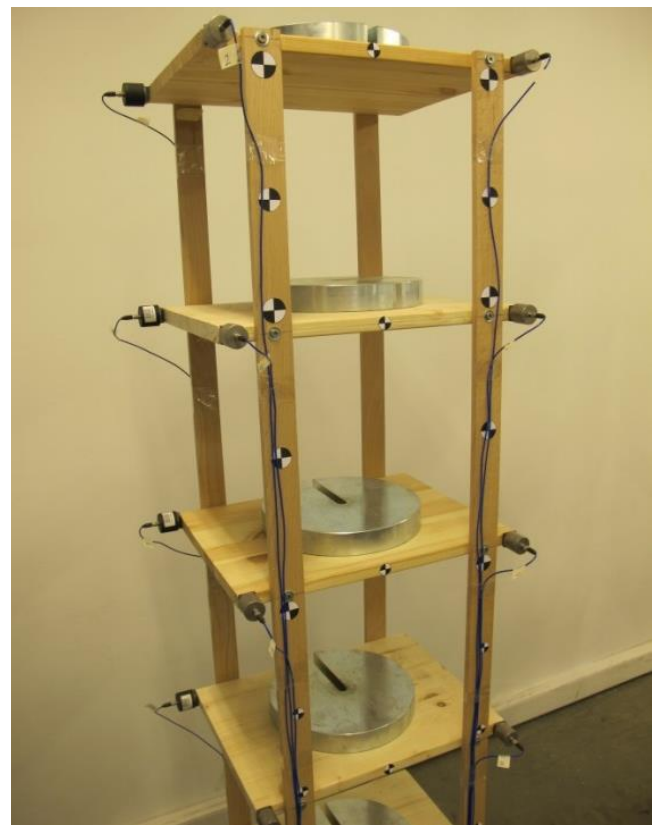

Şekil 2:

Test edilen model üzerine yerleştirilen ă̆ırlıklar ve sensörler

Deney düzeneği aşağıda Şekil 3'de gösterilmektedir. Lazer titreşim ölçer ve taşıyıcı platform bir tripod üzerine yerleştirilmiştir. Deneyler sırasında ölçümler yapıya 10 metre uzaklıkta konumlandırılmış olan sistem tarafından alınmıştır. Şekil 3'de ise deney düzeneğini gösteren tüm bileşenlerin birlikte gösterilebilmesi amacıyla platform yapıya yaklaştırılmıştır.

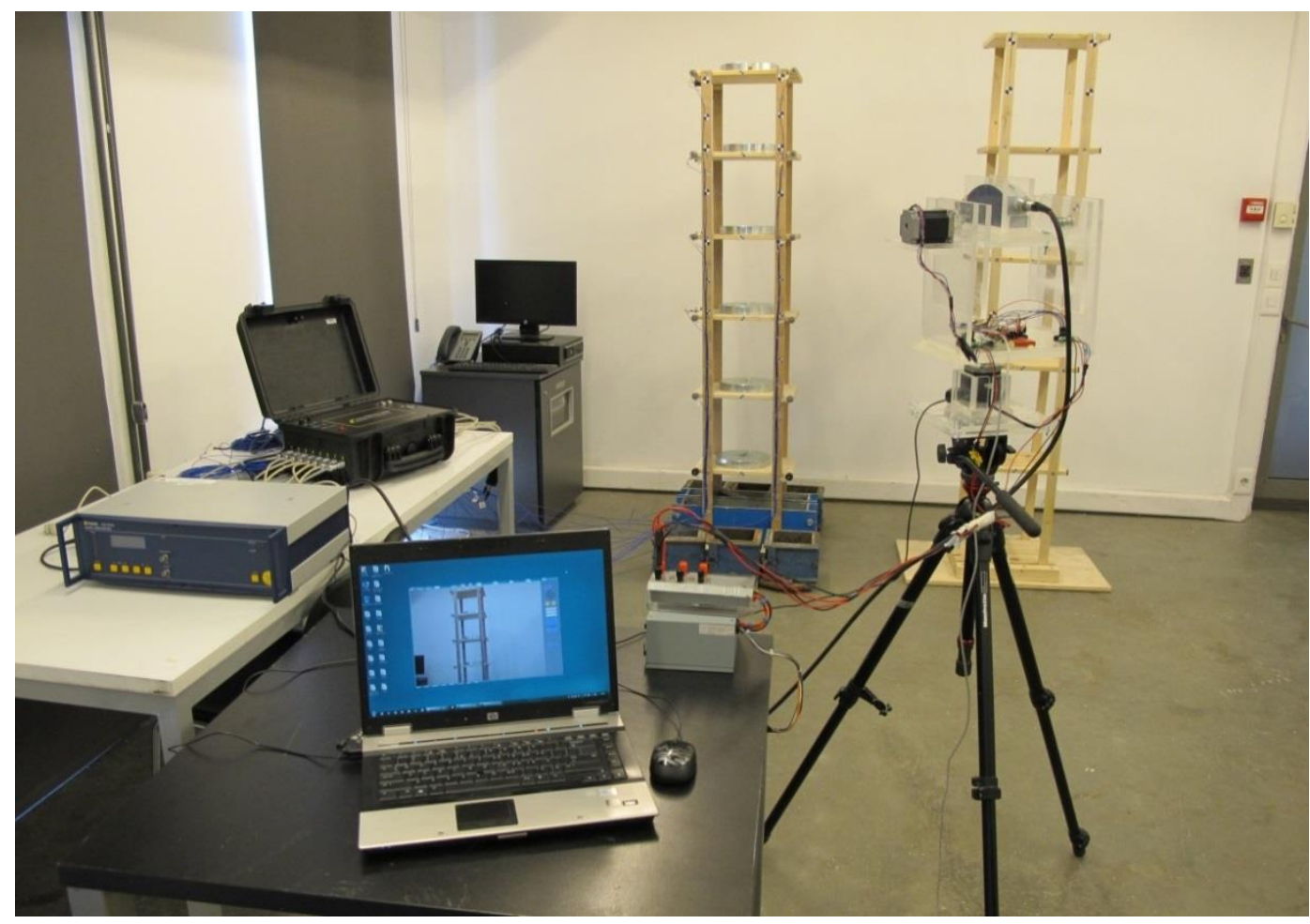

Şekil 3:

Deney düzeneği ve veri toplama sistemi 


\section{VERİ ANALIZİ ve SISTEM TANILAMA}

Gerçekleştirilen testler sonucu elde edilen titreşim verisi, Artemis Modal programı kullanılarak analiz edilmiştir. Bu yazılımda sistem geometrisi, sensör konumları ve ölçüm yönleri tanımlanarak, test edilen yapının bir bilgisayar modeli oluşturulmaktadır. Modelin kurulmasını takiben kaydedilen titreşim verisi çeşitli dinamik analiz yöntemleriyle çözümlenerek frekans, sönümleme oranları ve mod şekilleri gibi modal parametreler hesaplanmakta ve karşılaştırmalı olarak incelenebilmektedir. Kaydedilen 3 boyutlu titreşim verisinin analizi sonucu aşağıda Tablo 1 'de özetlenen titreşim modları gözlemlenebilmiştir.

Tablo 1. Analizler Sonucu Hesaplanan Modal Parametreler

\begin{tabular}{|l|c|c|c|}
\hline Titreşim Modu & Frekans (Hz) & Periyot (saniye) & Sönümleme Oranı (\%) \\
\hline X yönlü 1. Eğilme Modu & 1,34 & 0,746 & 2,95 \\
\hline Y yönlü 1. Eğilme Modu & 3,35 & 0,299 & 2,52 \\
\hline X yönlü 2. Eğilme Modu & 4,70 & 0,213 & 1,93 \\
\hline Burulma Modu 1 & 5,97 & 0,168 & 2,37 \\
\hline X yönlü 3. Eğilme Modu & 9,13 & 0,110 & 2,09 \\
\hline Y yönlü 2. Eğilme Modu & 13,08 & 0,076 & 1,64 \\
\hline X yönlü 4. Eğilme Modu & 14,53 & 0,069 & 1,73 \\
\hline X yönlü 5. Eğilme Modu & 20,32 & 0,049 & 3,37 \\
\hline Burulma Modu 2 & 21,73 & 0,046 & 1,45 \\
\hline
\end{tabular}

\subsection{Lazer Titreşimölçer Yardımıyla Yapının Taranması}

Yap1 üzerine yerleştirilen ivmeölçerler kat hizalarına sabitlenmiş olup düşey yönde aralarında $300 \mathrm{~mm}$ uzaklık bulunmaktadır. Eğer gerekli görülürse, $300 \mathrm{~mm}$ 'lik ölçüm çözünürlüğü (spatial resolution) daha fazla sayıda ivmeölçer kullanılarak artırabilir, ancak bu seçenek deney düzeneklerinin daha da karmaşıklaşmasına ve test süre ve maliyetlerinin artmasına yol açacaktır. Bu çalışmada önerilen sistem sayesinde ise gerekli görülen yüksek ölçüm çözünürlüğü ve hassasiyetine kolaylıkla ulaşılabilmektedir. Yap1 üzerine herhangi bir sensör yerleştirilmesine gerek olmadan dinamik test ve ölçümler çok kısa sürelerde ve düşük maliyetlerde tamamlanabilmektedir.

Gerçekleştirilen testlerde lazer titreşimölçer, yapıyı tarayıp $50 \mathrm{~mm}$ aralıklarla ölçüm alacak şekilde programlanmıştır. İki ölçüm noktası arasındaki bu mesafe gerek duyulursa daha da azaltılarak, nokta sayısı artırılabilir. Teorik olarak ölçüm noktalarının sayısı ile ilgili bir üst sınır bulunmamaktadır. Seçilen bu çözünürlük seviyeleriyle, yapının temel seviyesinden en üst noktasına kadar olan mesafede, ivmeölçer kullanılarak 6, lazer titreşimölçer kullanılarak ise 36 farklı noktadan ölçüm alınmıştır. Bu sayede ölçüm çözünürlüğünün 6 kat artırılması ve mod şekillerinin çok daha detaylı bir şekilde hesaplanabilmesi mümkün olmuştur. Yapısal sağlık takibi uygulamalarında elde edilen sonuçların güvenilirliği ölçüm noktası sayısı ile doğrudan bağlantılı olduğundan, lazer tarama yöntemleriyle çok daha kesin ve yüksek doğrulukta tahminler yapılması beklenmektedir. 
Aşağıda Şekil 4'de X Yönlü 1. Eğilme Modu için ivmeölçer ve lazer titreşimölçer kullanılarak hesaplanan mod şekilleri karşılaştırılmaktadır. Şekilde mavi renkte çizilen grafik ivmeölçer verisinden elde edilen mod șeklini göstermektedir ve modal büyüklükler 6 farklı nokta için hesaplanmıştır. Kırmızı renkte çizilen grafik ise lazer ölçümlerinden elde edilen mod şeklini göstermektedir ve modal büyüklükler 36 farklı nokta için hesaplanmıştır. Şekilden de anlaşılacağı üzere lazer ölçümleri ivmeölçer sonuçlarıyla örtüşmektedir ve çok daha yüksek bir çözünürlüğe sahiptir.

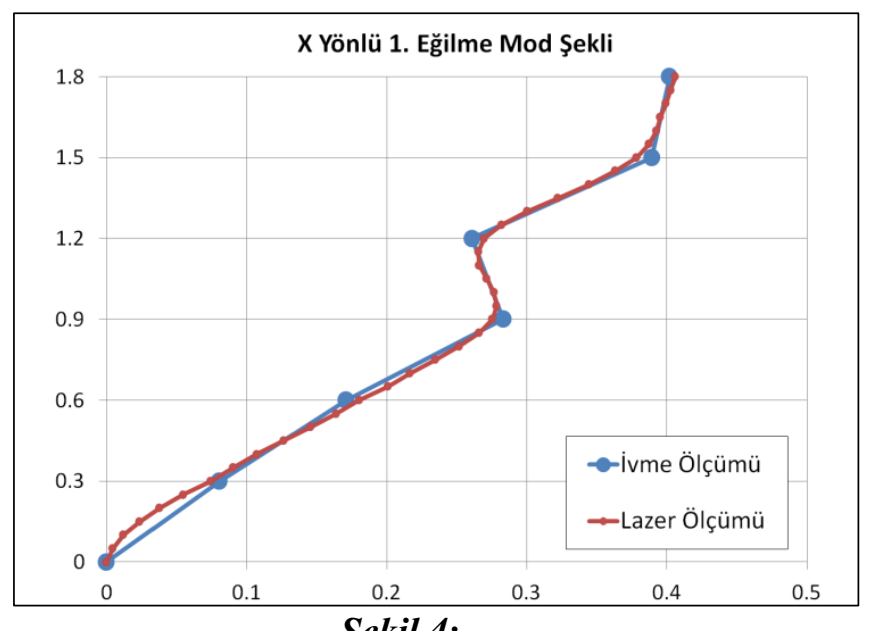

Ĕ̈ilme Modu 1 için ivmeölçer ve lazer titreşimölçer sonuçlarının karşılaşstırılması

Şekil 4'de 4. kat seviyesinde görülen sapma, yapısal kökenli olup modelin yapıldığı ahşap malzemeler arasındaki farklılıklardan kaynaklanabileceği düşünülmektedir. Modeli taşıyan 4 ahşap kolon benzer özellikte malzemelerden yapılmakla beraber, özellikle Elastisite Modüllerinde karşılaşılabilecek farklılıklar veya küçük çatlaklar gibi yapısal kusurlar gözlemlenen etkiye yol açabilir. Testler sırasında hem ivme hem de lazer ölçümleri benzer sonuçlar verdiği için bu sapmanın ölçümlerle veya kullanılan hesaplama metotlarıyla ilgili olmadığı düşünülmektedir.

Aşağıda Şekil 5'de 2. Eğilme Modu için ivmeölçer ve lazer titreşimölçer kullanılarak hesaplanan mod şekilleri karşılaştııılmaktadır. Lazer ölçümleri sahip oldukları yüksek çözünürlük sebebiyle, mod şekillerinde hasar sonucu oluşabilecek değişiklikleri çok daha çabuk ve yüksek hassasiyette tespit edebilmektedir.

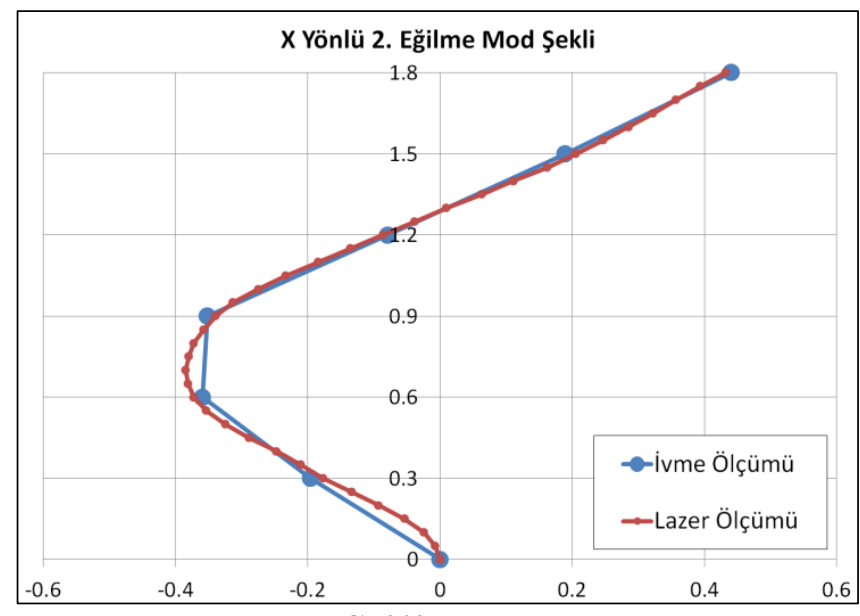

Şekil 5:

Eğilme Modu 2 için ivmeölçer ve lazer titreşimölçer sonuçlarının karşılaştırılması 
Benzer bir karşılaştırma 3. Eğilme Modu için Şekil 6'de ve 4. Eğilme Modu için ise Şekil 7'de yapılmaktadır. Özellikle yüksek modlarda titreşim şekli karmaşıklaştıkça, mod şekillerinin yüksek bir doğrulukla hesaplanabilmesi ve mod şekillerinde gözlemlenecek değişmelerin daha iyi takip edilebilmesi için ölçüm noktası sayısının artırılması bir zorunluluk haline gelmektedir. Önerilen sistem ihtiyaç duyulan bu yüksek çözünürlügü rahatll1ıkla sağlayacak kapasiteye sahiptir.

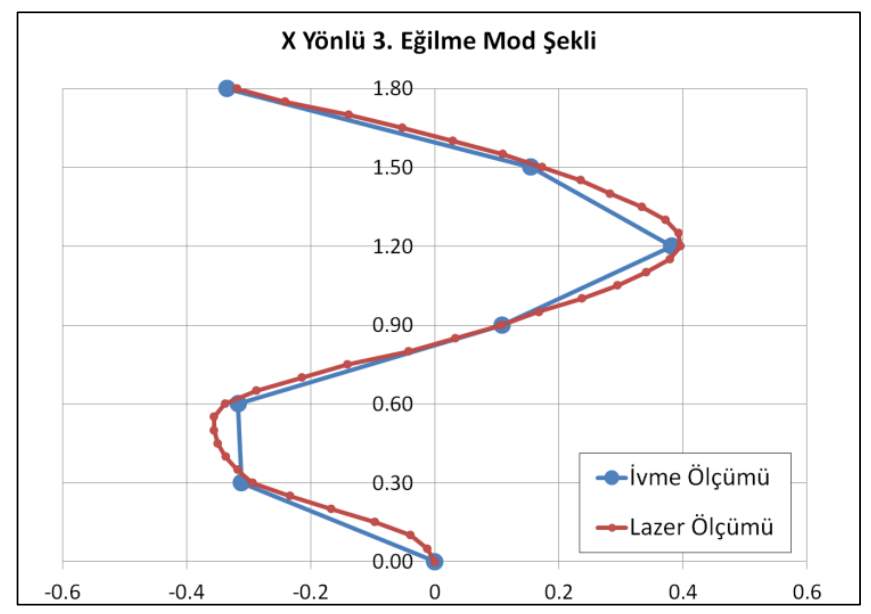

Şekil 6:

Ĕ̈ilme Modu 3 için ivmeölçer ve lazer titreşimölçer sonuçlarının karşılaşstırılması

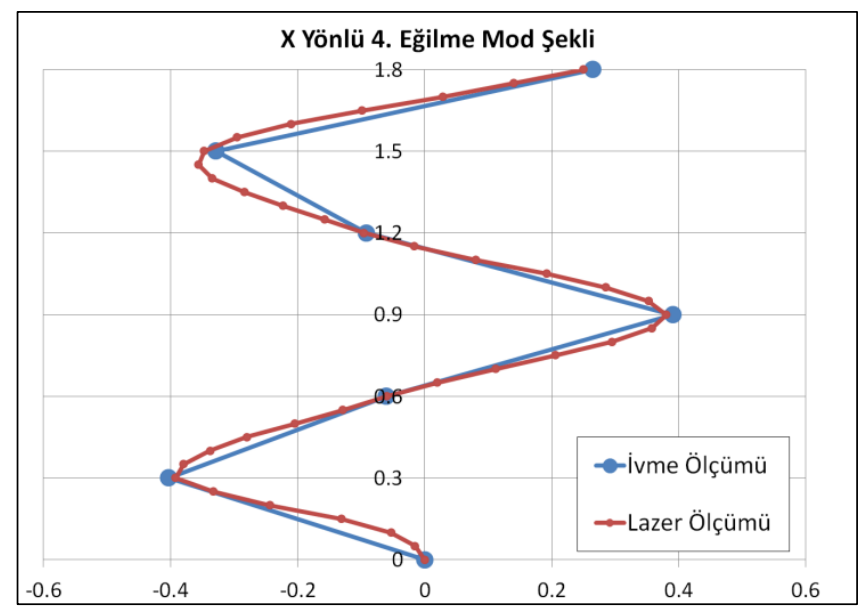

Şekil 7:

Eğilme Modu 4 için ivmeölçer ve lazer titreşimölçer sonuçlarının karşılaştırılması

\section{SONUÇLAR}

Yapısal sağlık takibi uygulamaları, kullanılan matematiksel metotlar açısından farklılıklar göstermekle beraber, temel olarak yapıya ait titreşim frekans1, sönümleme oranları ve mod şekilleri gibi dinamik parametrelerin düzenli olarak takip edilmesi esasına dayanmaktadır. Elde edilen bu parametrelerin sahip olduğu hassasiyet ve çözünürlük, yapının anlık durumuyla ilgili çıarılabilecek sonuçların güvenilirliğini doğrudan etkilemektedir. İhtiyaç duyulan bu çözünürlüğe ivmeölçer, gerinim ölçer gibi klasik sensör türleriyle ulaşılması teknik olarak 
mümkün olsa bile karmaşık deney düzeneklerinin kullanılmasını gerektirmekte ve gerçekleştirilen test ve ölçümlerin süresini ve maliyetlerini önemli ölçüde artırmaktadır.

Bu çalışmada yukarıda bahsedilen problemlere bir çözüm sağlaması amacıyla yeni bir lazer tarama sistemi geliştirilmesi amaçlanmıştır. Ölçüm lazeri olarak çeşitli yüzeylerden yüksek yansıma yoğunluğuna sahip olması sebebiyle kızılötesi IR (Infra-red) lazer tercih edilmiștir. IR lazer, mevcut tarama fonksiyonlu titreşimölçerlerde kullanılan görünür dalga boyundaki yeşilkırmızı lazerlerden farklı olarak ayna ve mercek gibi optik sistemlerle yönlendirilemez. Bu sebeple IR lazerin tarama modunda kullanılmasını mümkün kılacak yeni bir metot geliştirilmiş ve doğrudan lazer kaynağının hedefe yönlendirilmesini sağlayacak motorize bir platform tasarlanmıştır.

IR lazer normal gözle görülemediği için, laboratuvarda gerçekleştirilen ilk yapılabilirlik testlerinde, geliştirilen platformun etkinliği yine görünür dalgaboyunda kırmızı ölçüm lazerine sahip bir titreşimölçer kullanılarak test edilmiştir. Geliştirilen özel bir yazılım ve arayüz yardımıyla platformun hareketi kontrol edilebilmekte ve test süresi ve ölçüm noktaları gibi parametreler belirlenebilmektedir. Deneyler sırasında tarayıcı, yapı üzerinde düşey yönde 50 mm aralıklarla 36 farklı noktadan ölçüm alacak şekilde programlanmıştır. Bu sayede ivmeölçerlerle elde edilen $300 \mathrm{~mm}$ ölçüm çözünürlüğü 6 kat artırılabilmiştir. Teorik olarak ölçüm noktalarının sayısı ile ilgili bir üst sınır bulunmamaktadır.

Elde edilen titreşim datasının analizleri sonucunda mod şekilleri hesaplanmış ve ivmeölçer ve lazer titreşimölçerden elde edilen şekiller karşılaştırılmalı olarak sunulmuştur. Lazer titreşimölçer kullanılarak hesaplanan değerlerin sayısal olarak ivme ölçümleriyle örtüştüğü ve daha yüksek bir çözünürlüğe sahip olduğu gösterilmiştir. Geliştirilen sistem, özellikle yüksek modlarda titreşim şekli karmaşıklaştıkça mod şekillerinde gözlemlenecek değişmelerin takip edilebilmesini mümkün kılmaktadır.

\section{KAYNAKLAR}

1. Bocca, M., Eriksson, L., Mahmood, A., Jäntti, R. ve Kullaa, J. (2011) A synchronized wireless sensor network for experimental modal analysis in structural health monitoring, Computer-Aided Civil and Infrastructure Engineering, 26(7), 483-499. doi:10.1111/j.14678667.2011.00718.x

2. https://www.polytec.com/int/, Erişim Tarihi: 20.07.2018, Konu: Lazer Titreşimölçerler.

3. Krishnamurthy, V., Fowler, K. ve Sazonov, E. (2008) The effect of time synchronization of wireless sensors on the modal analysis of structures, Smart Materials and Structures, 17(5) 055018. doi: 10.1088/0964-1726/17/5/055018

4. Magalhães, F. ve Cunha, Á. (2016) Automated identification of the modal parameters of a cable-stayed bridge: Influence of the wind conditions, Smart Structures and Systems, 17(3), 431-444. doi:10.12989/sss.2016.17.3.431

5. Nickitopoulou, A., Protopsalti, K. ve Stiros, S. (2006) Monitoring dynamic and quasi-static deformations of large flexible engineering structures with GPS: Accuracy, limitations and promises, Engineering Structures, 28(10), 1471-1482. doi:10.1016/j.engstruct.2006.02.001

6. Oliveira, G., Magalhães, F., Cunha, Á. ve Caetano, E. (2018), Continuous dynamic monitoring of an onshore wind turbine, Engineering Structures, 164, 22-39. doi:10.1016/j.engstruct.2018.02.030

7. Tamura, Y., Matsui, M., Pagnini, L.C., Ishibashi, R. ve Yoshida A (2002). Measurement of wind-induced response of buildings using RTK-GPS, Journal of Wind Eng. Ind. Aerodyn, 90(12-15), 1783-93. doi:10.1016/S0167-6105(02)00287-8 
Özbek M. ve Gökdel Y.D.: Çok Katılı Yapılarda Robotik Lazer Tarayıcı Sistemlerle Yapısal Sağlık Takibi

8. Yang, S., Allen ve M.S. (2012), Output-only Modal Analysis using Continuous-Scan Laser Doppler Vibrometry and application to a $20 \mathrm{~kW}$ wind turbine, MSSP Mechanical Systems and Signal Processing, 31, 228-245. doi:10.1016/j.ymssp.2012.04.012 